OPEN ACCESS

Edited by: John O. Prior Lausanne University Hospital, Switzerland

Reviewed by: Ferid Haddad, Université de Nantes, France Christiaan Vermeulen, Los Alamos National Laboratory (DOE), United States

*Correspondence: Susanta Lahir susanta.lahiri.sinp@gmail.com

Specialty section This article was submitted to Nuclear Medicine, a section of the journal Frontiers in Medicine

Received: 02 March 2021 Accepted: 06 April 2021 Published: 31 May 2021

\section{Theranostic Terbium Radioisotopes: Challenges in Production for Clinical Application}

\author{
Nabanita Naskar and Susanta Lahiri* \\ Chemical Sciences Duvision, Saha Institute of Nuclear Physics, Kolkata, India
}

Currently, research on terbium has gained a momentum owing to its four short-lived radioisotopes, ${ }^{149} \mathrm{~Tb},{ }^{152} \mathrm{~Tb},{ }^{155} \mathrm{~Tb}$, and ${ }^{161} \mathrm{~Tb}$, all of which can be considered in one or another field of nuclear medicine. The members of this emerging quadruplet family have appealing nuclear characteristics and have the potential to do justice to the proposed theory of theranostics nuclear medicine, which amalgamates therapeutic and diagnostic radioisotopes together. The main challenge for in vivo use of these radioisotopes is to produce them in sufficient quantity. This review discusses that, at present, neither light charged particle nor the heavy ion $(\mathrm{HI})$ activation are suitable for large-scale production of neutron deficient terbium nuclides. Three technological factors like (i) enrichment of stable isotopes to a considerable level, (ii) non-availability of higher energies in commercial cyclotrons, and (iii) non-availability of the isotope separation technique coupled with commercial accelerators limit the large scale production of terbium radionuclides by light charged particle activation. If in future, the technology can overcome these hurdles, then the light charged particle activation of enriched targets would produce a high amount of useful terbium radionuclides. On the other hand, to date, the spallation reaction coupled with an online isotope separator has been found suitable for such a requirement, which has been adopted by the CERN MEDICIS programme. The therapeutic ${ }^{161} \mathrm{~Tb}$ radionuclide can be produced in a reactor by neutron bombardment on enriched ${ }^{160} \mathrm{Gd}$ target to produce ${ }^{161} \mathrm{Gd}$ which subsequently decays to ${ }^{161} \mathrm{~Tb}$. The radiochemical separation is mandatory even if the ISOL technique is used to obtain high radioisotopic purity of the desired radioisotope.

Keywords: $149,152,155,161 \mathrm{~Tb}$, theranostic radioisotopes, light charged particle activation, heavy ion activation, spallation reaction, radiochemical separation

\section{INTRODUCTION}

The discipline of "Nuclear Medicine" has passed through a "series of growth phases" since its inception. The present growth phase of nuclear medicine is about the fascinating progress of the discipline in the direction of theranostics (1).

$$
\text { Theranostics }=\text { Therapeutic }+ \text { Diagnostic }
$$

The term "theranostics" was first coined by John Funkhouser in a 1998 press release, in the context of personalized treatment $(2,3)$. It is a holistic and tailor-made pharmacotherapy that 
enhances the therapeutic effects with efforts to reduce treatment toxicities. In nuclear medicine, theranostics refers to the pairing of therapeutic-diagnostic radioactive candidates chelated to a compound (carrier/vector) and targeted toward any particular clinical condition. Therapeutic radioisotopes decay by releasing a particle like $\alpha / \beta^{-}$/auger electrons, which are capable of ionization or bond-breakage, whereas diagnostic radioisotopes decay by releasing gamma rays or emit gamma rays after annihilation of $\beta^{+}$, which are used for imaging purposes. Ideally, a theranostic pair in nuclear medicine should be composed of radioisotopes derived from the same element, one serving as a therapeutic agent and another aiding in diagnosis. Practically, such conjugation has to pass through stringent scrutiny before being referred to as a proper theranostic radiopharmaceuticals (RP), $(\mathrm{RP}=$ Radiotracer + Carrier/Vector).

While explaining such theranostic candidates, Schottelius et al. (4) have used the term "twins in spirit" for a pair which may or may not be chemically or biologically identical but the diagnostic counterpart can effectively predict the bio-distribution of the therapeutic radionuclide. A few examples would be helpful to visualize the concept of a "matched pair." So-called matched pairs or theranostic pairs include: ${ }^{43 / 44} \mathrm{Sc}-{ }^{47} \mathrm{Sc},{ }^{64} \mathrm{Cu}-{ }^{67} \mathrm{Cu},{ }^{72} \mathrm{As}-$ ${ }^{77} \mathrm{As},{ }^{83} \mathrm{Sr}-{ }^{89} \mathrm{Sr},{ }^{86} \mathrm{Y}-{ }^{90} \mathrm{Y},{ }^{124} \mathrm{I}-{ }^{131} \mathrm{I},{ }^{203} \mathrm{~Pb}-{ }^{212} \mathrm{~Pb}$, etc. (5-8). All of these pairs have the combination of $\beta^{+}-\beta^{-} .{ }^{86} \mathrm{Y}-{ }^{90} \mathrm{Y}$ was the first matched pair being used for theranostic purposes. In this pair, ${ }^{86} \mathrm{Y}\left(T_{1 / 2}=14.7 \mathrm{~h}\right)$ provided the $\beta^{+}\left(\beta^{+}=31.9 \%\right.$, $\mathrm{EC}=68.1 \%)$ used for imaging and ${ }^{90} \mathrm{Y}\left(T_{1 / 2}=2.7 \mathrm{~d}\right)$ is the $\beta^{-}$emitter $(100 \%)$ that acted as the therapeutic part. Presently, the theranostic pair of ${ }^{68} \mathrm{Ga}-{ }^{177} \mathrm{Lu}$ has achieved great success and is in routine use for treatment of neuroendocrine tumors (NET). ${ }^{68} \mathrm{Ga}\left(T_{1 / 2}=67.6 \mathrm{~min} ; 89 \%\right.$ positron branching) is a common PET candidate and is readily available from the ${ }^{68} \mathrm{Ge} /{ }^{68} \mathrm{Ga}$ generator system. ${ }^{68} \mathrm{Ga}$-tracers, chelated with ligands like peptides, proteins, or antibodies, are in use for several diagnostic applications (9). On the other hand, the therapeutic counterpart, ${ }^{177} \mathrm{Lu}\left(T_{1 / 2}=6.7 \mathrm{~d}\right)$ is a beta-emitter. In a ${ }^{68} \mathrm{Ga}$ ${ }^{177} \mathrm{Lu}$ combination, ${ }^{68} \mathrm{Ga}$ does the imaging along with receptor visualization and antigen expression and ${ }^{177} \mathrm{Lu}$ is utilized for radiotherapy (10). For treatment of NET in patients, peptide receptor radionuclide therapy (PRRT) is usually preferred. In PRRT, peptide molecule like octreotide (somatostatin analog), covalently bound to chelators (DOTA, NOTA, etc.), enables the coordination of $\beta^{+}\left({ }^{68} \mathrm{Ga}\right)-\beta^{-}\left({ }^{177} \mathrm{Lu}\right)$ candidates.

Though matched pairs hold a brighter prospect and some combinations are in the pre-clinical or trial phase, broad

Abbreviations: ALARA, As Low As Reasonably Achievable (taking economic and social factors into account); DNA, Deoxyribonucleic Acid; DOTA, Dodecane Tetraacetic Acid (1,4,7,10-tetraazacyclododecane-1,4,7,10-tetraacetic acid); DTPA, diethylenetriamine pentaacetic acid; EC, Electron Capture; EOB, End of Bombardment; EOC, End of Collection; HDEHP, di-(2-ethylhexyl) phosphoric acid; HI, Heavy Ion; HIBA, $\alpha$-hydroxy butyric acid; ISOL, Isotope Separation Online; LBE, Lead Bismuth Eutectic; LET, Linear Energy Transfer; LLX, Liquid Liquid Extraction; Mab, Monoclonal Antibody; NCA, No-Carrieradded; NET, Neuro Endocrine Tumor; NOTA, Nonane Tetraacetic Acid (1,4,7triazacyclononane-1,4,7-triacetic acid); PET, Positron Emission Tomography; PRRT, Peptide Receptor Radionuclide Therapy; RBE, Relative Biological Effectiveness; RIB, Radioactive Ion Beam; RP, Radiopharmaceutical; SPECT, Single-Photon Emission Computed Tomography; TAT, Targeted Alpha Therapy. level administration is still a constraint and requires more experiments, practical knowledge, and easy availability of the concerned radioisotopes.

In recent years, research on various terbium radionuclides has been carried out mainly by the physics and chemistry community in and around Geneva. Terbium is referred as the "Swiss knife" because of its four valuable radioisotopes, ${ }^{149} \mathrm{~Tb},{ }^{152} \mathrm{~Tb},{ }^{155} \mathrm{~Tb}$, and ${ }^{161} \mathrm{~Tb}$. Despite their lucrative nuclear properties useful in diagnosis and therapy and their evolvement as successful theranostic pair; radionuclidic therapy with terbium radionuclides is still a challenge due to their low production cross section. Due to unavailability of these radionuclides in sufficient quantities, at the moment, only few works have been reported related to pre-clinical and clinical studies with terbium radionuclides.

After a brief introduction of these four radionuclides, this review discusses the methods of production of important terbium radionuclides by light and heavy ion induced reactions as well as a spallation reaction followed by the separation of these radionuclides from the target matrix whenever required.

\section{BRIEF INTRODUCTION TO RADIOTHERAPY}

Radiotherapy can be achieved in conjugation with $\alpha$-, $\beta$-, or Auger electron emitters. The $\alpha$-particles have high energy $(\sim 4-$ $9 \mathrm{MeV}$ ), and high linear energy transfer (LET $>20$ to hundreds of $\mathrm{keV} / \mu \mathrm{m})$. The possibility of ionization per unit path length is very high for $\alpha$-particles and therefore cytotoxicity is $5-100$ times higher as compared to $\beta$-particles. Because of higher cytotoxicity and the probability of a large number of ionizations, only with few $\alpha$-particle emissions, effective cell killing is achieved (11) (Figure 1). Alpha particles are generally suitable for small tumors, isolated, or micro-clustered tumors because of their short path-length $(40-100 \mu \mathrm{m} ; \sim 1-3$ cell diameter). The $\alpha$ emitting radionuclides like ${ }^{211} \mathrm{At}(7.21 \mathrm{~h}),{ }^{212} \mathrm{Bi}(60.55 \mathrm{~min}),{ }^{213} \mathrm{Bi}$ (45.6 min), ${ }^{225} \mathrm{Ac}(10 \mathrm{~d}),{ }^{212} \mathrm{~Pb}(10.64 \mathrm{~h}),{ }^{223} \mathrm{Ra}(11.43 \mathrm{~d})$, and ${ }^{149} \mathrm{~Tb}(4.12 \mathrm{~h})$ can essentially be used in cancer therapy.

On the other side, the $\beta$-particles have medium to high mean energy $(0.5-2.3 \mathrm{MeV})$ and low LET $(\sim 0.2 \mathrm{keV} / \mu \mathrm{m})$. They have a longer path-length ( $\mu \mathrm{m}$ to few $\mathrm{cm}$, i.e., $\sim 5-150$ cell diameter), are approximately in tissue-level range, and therefore may be suitable for large tumors or macro-clusters.

Use of Auger electrons was first proposed by Feinendegen (12). The Auger electrons are very low-energy electrons $(\mathrm{eV}-$ $\mathrm{keV}$ ) having considerable LET. Their path-length is at subcellular range $(\mathrm{few} \mu \mathrm{m}$ ). If the Auger electron emitting radionuclide is internalized in the cell nucleus with the help of a suitable vector, then maximum energy deposition occurs close to the cell nucleus. The conversion or Auger electrons are generally suitable for isolated or micro-clusters (13-15). Therapy with Auger electrons is still at its nascent phase and requires much more understanding related to its bio-distribution kinetics at the subcellular level.

The alpha particles have high LET, lower path length/range and high relative biological effectiveness (RBE) (16). Alpha particles are capable of creating dense ionization tracks on DNA 

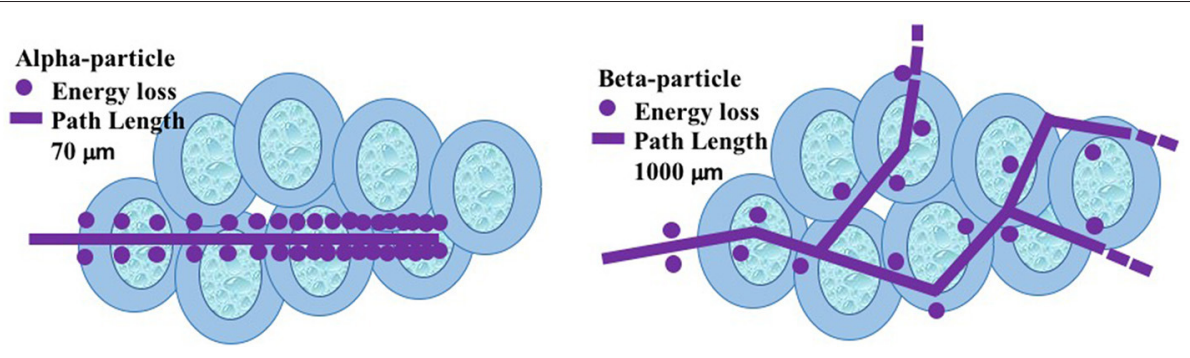

FIGURE 1 | Path lengths of alpha- and beta- particles at target site.

TABLE 1 | Some potential radio-lanthanides proposed in nuclear medicine.

\begin{tabular}{|c|c|c|c|c|}
\hline $\begin{array}{l}\text { Radio-lanthanides } \\
\text { (half-life)* }\end{array}$ & $\begin{array}{l}\text { Decay modes } \\
\text { (branching ratio)* }^{*}\end{array}$ & Gamma-energy, $\operatorname{keV}\left(\mathrm{I}_{\gamma}, \%\right)^{\star}$ & $\beta_{\text {end point }}$ energy, $\operatorname{keV}\left(\mathbf{I}_{\gamma}, \%\right)^{*}$ & Application \\
\hline${ }^{134} \mathrm{La}(6.5 \mathrm{~min})$ & $\beta^{+}(63 \%) ; \mathrm{EC}(37 \%)$ & 605 (5.0), $511.0(127.2)$ & $2,709(62.0)$ & Imaging \\
\hline${ }^{140} \mathrm{La}(1.7 \mathrm{~d})$ & $\beta^{-}(100 \%)$ & $\begin{array}{c}328.8(20.3), 487.0(45.5), 815.8(23.3) \\
1596.2(95.4)\end{array}$ & $\begin{array}{c}\text { 1,239 (11.0), 1,348 (43.9), 1,677 } \\
(20.2)\end{array}$ & Therapy \\
\hline${ }^{141} \mathrm{Ce}(32.5 \mathrm{~d})$ & $\beta^{-}(100 \%)$ & $145.44(48.2)$ & 435 (69.7), 580 (30.3) & Tracer studies \\
\hline${ }^{140} \operatorname{Pr}(3.4 \mathrm{~min})$ & $\beta^{+}(51 \%) ;$ EC (49\%) & $511.0(102.0)$ & $2,366(51.0)$ & Imaging \\
\hline${ }^{143} \operatorname{Pr}(13.6 \mathrm{~d})$ & $\beta^{-}(100 \%)$ & No good gamma-energy & $934(100)$ & Therapy \\
\hline${ }^{144} \operatorname{Pr}(17.3 \mathrm{~min})$ & $\beta^{-}(100 \%)$ & No good gamma-energy & 2,997 (97.9) & Therapy \\
\hline${ }^{149} \mathrm{Pm}(53.1 \mathrm{~h})$ & $\beta^{-}(100 \%)$ & $285.9(3.1)$ & $1,071(95.9)$ & Therapy \\
\hline${ }^{157}$ Dy $(8.1$ h) & EC (100\%) & $326.2(92)$ & - & Imaging \\
\hline${ }^{165}$ Dy $(2.3 h)$ & $\beta^{-}(100 \%)$ & $94.7(3.6)$ & 1,192 (15), 1,287 (83.0) & Therapy \\
\hline${ }^{166}$ Dy (81.6 h) & $\beta^{-}(100 \%)$ & $82.5(14)$ & $404(97.0)$ & Therapy \\
\hline${ }^{166} \mathrm{Ho}(26.8 \mathrm{~h})$ & $\beta^{-}(100 \%)$ & $80.6(6.7)$ & 1,774 (49.9), 1,855 (48.8) & Therapy \\
\hline${ }^{167} \operatorname{Tm}(9.2 \mathrm{~d})$ & EC (100\%) & $207.8(42)$ & - & Imaging \\
\hline${ }^{170} \mathrm{Tm}(128.6 \mathrm{~d})$ & $\beta^{-}(99.86 \%)$, EC $(0.13 \%)$ & $84.2(2.5)$ & $968(81.9)$ & Therapy \\
\hline${ }^{172} \mathrm{Tm}(63.6 \mathrm{~h})$ & $\beta^{-}(100 \%)$ & 1093.6 (6.0), 1387.1 (5.6), 1529.7 (5.1) & 414 (10.1), 1,801 (36), 1,880 (29) & Therapy \\
\hline${ }^{169} \mathrm{Yb}(32.0 \mathrm{~d})$ & EC (100\%) & $\begin{array}{c}109.8(17.5), 130.5(11.3), 177.2(22.2) \\
197.9(35.8), 307.7(10.0)\end{array}$ & - & Therapy \\
\hline${ }^{177} \mathrm{Lu}(6.7 \mathrm{~d})$ & $\beta^{-}(100 \%)$ & 112.9 (6.4), 208.36 (11) & 175 (11.7), 384 (8.9), 497 (79.4) & Therapy \\
\hline
\end{tabular}

*https://www.nndc.bnl.gov/nudat2/ (21).

double strands that results in clusters of DNA damage. Such complex damage results in chromosome aberration, impairment in reproductive integrity of any cell (cell cycle arrest is shorter), etc. Such damages are more genotoxic and resistant to normal repair, resulting in high probability of cell death. Approximately $100-200 \mathrm{keV} / \mu \mathrm{m}$ LET is required for double strand break at the maximum rate, whereas low LET or gamma radiations result in sparsely distributed DNA breaks (17-20). It is noteworthy to mention that the beta particles and alpha particles are complementary to each other, the former is more interesting for diffuse or residual diseases, the latter one can be used in $\mathrm{mm}$ size clusters of cancer cells. However, to date, $\beta^{-}$emitters are more popular in therapy rather than $\alpha$ emitting radionuclides.

\section{INTRODUCTION TO TERBIUM RADIONUCLIDES}

Some of the radioisotopes of the lanthanide series exhibit suitable half-lives and distinct modes of decay schemes relevant to nuclear medicine (Table 1). The importance of radio-lanthanides in the field of nuclear medicine was elaborately reviewed in 1999 (22). In the last 20 years, the radioisotopes of two lanthanide elements, $\mathrm{Tb}$ and $\mathrm{Lu}$, came in the forefront. ${ }^{177} \mathrm{Lu}$ is now regularly being used in hospitals for in vivo administration to the patients for therapy. While four radioisotopes of terbium, ${ }^{149} \mathrm{~Tb},{ }^{152} \mathrm{~Tb},{ }^{155} \mathrm{~Tb}$, and ${ }^{161} \mathrm{~Tb}$ came into the center stage of discussion and have been revealed as some of the most powerful tools for both therapy and diagnosis in the near future. This review focuses on these four radioisotopes of terbium in the following section.

The research and interest on terbium radionuclides for human application has augmented many folds after the initiation of the CERN MEDICIS (Medical Isotopes Collected from ISOLDE) project. This new project aims to serve mankind by producing clinically important radionuclides to be supplied at the local hospitals. The project was conceptualized in 2012 (23) and on January 15, 2018, CERN announced that the CERN-MEDICIS facility had produced its first radioisotope, a batch of terbium $\left({ }^{155} \mathrm{~Tb}\right)$, part of the ${ }^{149,152,155,161} \mathrm{~Tb}$ family (24). 
TABLE 2 | Properties of four terbium radioisotopes [21, 25].

\begin{tabular}{|c|c|c|c|c|c|}
\hline $\begin{array}{l}\text { Radio-isotope } \\
\left(T_{1 / 2}\right)\end{array}$ & Decay modes & $\begin{array}{l}\text { Particle energy, } \\
E_{\alpha}(\mathrm{MeV})\end{array}$ & $\begin{array}{c}\text { Particle energy, } \\
E_{\beta a v g}(\mathrm{MeV})\end{array}$ & $E \gamma, \operatorname{keV} ;(\gamma \gamma \%)$ & Comment \\
\hline \multirow[t]{4}{*}{${ }^{149} \mathrm{~Tb}(4.12 \mathrm{~h})$} & EC (82.3 \%), $\alpha(17.7 \%)$ & $\begin{array}{l}3.97 \mathrm{MeV} \\
I_{\alpha}=16.7 \%\end{array}$ & $\begin{array}{l}0.730(\text { Total } \\
\left.I_{\beta+}=7.1 \%\right)\end{array}$ & $165.0(26.4)$ & $\begin{array}{c}\text { Path length in normal tissue }= \\
25-28 \mu \mathrm{m} \text {; LET }=140-142 \mathrm{keV} / \mu \mathrm{m} \text {, } \\
\text { use in } \alpha \text {-therapy and/or PET } \\
\text { (Annihilation } 511 \mathrm{keV}=14.2 \% \text { ) }\end{array}$ \\
\hline & & & & $352.2(29.4)$ & \\
\hline & & & & $388.6(18.4)$ & \\
\hline & & & & $652.1(16.2)$ & \\
\hline${ }^{152} \mathrm{~Tb}(17.5 \mathrm{~h})$ & $E C+\beta^{+}(100 \%)$ & - & $\begin{array}{c}1.140(\text { Total } \\
\left.I_{\beta+}=20.3 \%\right)\end{array}$ & $\begin{array}{c}271.1(9.5), 344.3(63.5) \\
586.3(9.2), 778.9(5.5)\end{array}$ & PET (Annihilation $511 \mathrm{keV}=41 \%$ ) \\
\hline${ }^{155} \mathrm{~Tb}(5.32 \mathrm{~d})$ & EC (100 \%) & - & - & $\begin{array}{c}105.3(25.1), 180.1(7.5) \\
262.3(5.3)\end{array}$ & SPECT \\
\hline${ }^{161} \mathrm{~Tb}(6.89 \mathrm{~d})$ & $\beta^{-}(100 \%)$ & - & $\begin{array}{l}0.154(\text { Total } \\
\left.\mathrm{I}_{\beta-}=101 \%\right)\end{array}$ & $\begin{array}{c}25.6(23.2), 48.9(17.0) \\
74.6(10.2)\end{array}$ & $\beta^{-}$and/or auger therapy \\
\hline
\end{tabular}

These four radioisotopes of terbium can provide suitable matched pairs for theranostic activities. The first in vivo proof-ofconcept in favor of the unique quadruplet family: ${ }^{149} \mathrm{~Tb},{ }^{152} \mathrm{~Tb}$, ${ }^{155} \mathrm{~Tb},{ }^{161} \mathrm{~Tb}$ was reported by Müller et al. (25). Because of identical chemical properties, formulation of RPs with identical pharmacokinetics for these species are easily possible. The potential uses of these four terbium isotopes are given below. Table 2 provides at-a-glance use of these radioisotopes.

\section{${ }^{149} \mathrm{~Tb}$}

It is the only $\alpha$-emitting radioisotope of $\mathrm{Tb}$ and became promising for targeted alpha therapy (TAT). With a tissue range of 25-28 $\mu \mathrm{m}$ and LET of 140-142 keV/ $\mu \mathrm{m}$, it can be conjugated with small-molecular weight carriers like peptides that are easily cleared from the body. ${ }^{149} \mathrm{~Tb}$ has additional features of emitting gamma rays $\left(E_{\gamma}=165 \mathrm{keV}, I_{\gamma}=26.4 \%\right)$, which helps in its detection. At the same time, ${ }^{149} \mathrm{~Tb}$ is also $\beta^{+}$emitter.

However, the major concern of ${ }^{149} \mathrm{~Tb}$-TAT is its large-scale production. Another important concern about ${ }^{149} \mathrm{~Tb}$-TAT is the decay scheme of ${ }^{149} \mathrm{~Tb}$ (Figure 2), which is quite complex. The daughter products of ${ }^{149} \mathrm{~Tb}$ are long-lived radionuclides, like ${ }^{149} \mathrm{Gd}(9.28 \mathrm{~d}),{ }^{145} \mathrm{Eu}(5.93 \mathrm{~d}),{ }^{145} \mathrm{Sm}(340 \mathrm{~d}),{ }^{149} \mathrm{Eu}(93.1 \mathrm{~d})$, etc. More research is required to elucidate any complexity arising due to in vivo presence of these ${ }^{149} \mathrm{~Tb}$-decay products. For example, a preliminary dose evaluation related to retention of residual radioactivity after injection of $1 \mathrm{GBq}{ }^{149} \mathrm{~Tb}$-rituximab conjugate in a patient's system was estimated at several time-intervals. It was estimated that after 1 year, $100 \mathrm{kBq}{ }^{149} \mathrm{Eu}, 41 \mathrm{kBq}{ }^{145} \mathrm{Sm}, 2.2$ $\mathrm{kBq}{ }^{145} \mathrm{Pm}$, and after 10 years, $50 \mathrm{~Bq}{ }^{145} \mathrm{Sm}, 3.1 \mathrm{~Bq}{ }^{145} \mathrm{Pm}$ will remain within the patient system (26). In such situations, biodistribution profiling should be at par with ALARA principle. Several trials need to be carried out to reduce toxicity to nontarget tissues.

\section{Tb}

${ }^{152} \mathrm{~Tb}$ is a multiple $\beta^{+}$- emitter with prominent end-point energies at 2,620 keV (5.9\%) and 2,970 keV (8\%). As a diagnostic tool, it is suitable for dosimetry and monitoring of ${ }^{149 / 161} \mathrm{~Tb}$-radioligands. ${ }^{152} \mathrm{~Tb}$ can be the companion PET isotope in combination with other therapeutic radioisotopes in a theranostic approach. ${ }^{152} \mathrm{~Tb}$ is also a potential SPECT candidate due its multiple gamma lines. At the same time this multiple gamma-rays emission is a drawback when it is used as PET isotope due to increased radiation burden (27). To understand the bio-kinetic behavior of radio-lanthanides in vivo, Beyer (28) probed the efficacy of ${ }^{149} \mathrm{~Tb}$ and ${ }^{152} \mathrm{~Tb}$ in PET imaging, where it was realized that scan quality with ${ }^{152} \mathrm{~Tb}$ is significantly better than that obtained for ${ }^{149} \mathrm{~Tb}$. Also, Beyer (28) indicated that ${ }^{152} \mathrm{~Tb}$ could be used for in vivo dosimetry to monitor ${ }^{149} \mathrm{~Tb}$ bio-distribution in radiotherapy.

\section{Tb}

This radionuclide is a potential SPECT candidate. It can provide insight into the malignancy stages and may also be used for dosimetry calculation prior to therapy. In a matched-pair of ${ }^{155} \mathrm{~Tb}-{ }^{161} \mathrm{~Tb},{ }^{155} \mathrm{~Tb}$ may be beneficial for pre-therapeutic imaging and dosimetry prior to targeted therapy by ${ }^{161} \mathrm{~Tb}$ (29). With $\gamma$-energies at $87 \mathrm{keV}(32 \%)$ and $105 \mathrm{keV}(25 \%),{ }^{155} \mathrm{~Tb}$ may have further applications in gamma camera scintigraphy (30). Recently, the clinical use of ${ }^{152} \mathrm{~Tb}$ - DOTATOC as human PET/CT agent was evaluated by Baum et al. (31).

\section{Tb}

${ }^{161} \mathrm{~Tb}$ has interesting decay characteristics that make it a promising radionuclide in nuclear oncology. ${ }^{161} \mathrm{~Tb}$ mainly decays by release of $\beta^{-}$particles, but it also emits Auger electrons. It is believed that high LET of Auger electrons can be effective in reducing the survival capacity of cancer cells. On an average, 2.24 Auger and conversion electrons are emitted along with one beta-particle per decay $(21,30)$. Based on the pre-clinical studies and comparison with ${ }^{177} \mathrm{Lu}$, use of ${ }^{161} \mathrm{~Tb}$ for cancer therapy showed minimal or nil side effects to kidneys (29). According to theoretical simulations, in many cases ${ }^{161} \mathrm{~Tb}$ proves to be a better therapeutic candidate when compared to prevalent standard and non-standard therapeutic radioisotopes (32). 




\section{PRODUCTION OF TERBIUM RADIONUCLIDES}

The production in sufficient amounts and its separation in a nocarrier-added (NCA) state from the target matrix are the two most important criteria for any radionuclide to be used in the field of nuclear medicine. But in practice, a hurdle lies in the production of terbium radionuclides in an adequate quantity [except ${ }^{161} \mathrm{~Tb}$, which can be produced in a reactor following a ${ }^{160} \mathrm{Gd}(\mathrm{n}, \gamma){ }^{161} \mathrm{Gd}\left(\beta^{-}\right){ }^{161} \mathrm{~Tb}$ reaction]. All possible production routes, i.e., (a) light ion induced reactions, (b) heavy ion induced reactions, and (c) spallation reactions have been exploited by scientists all over the world. Literature on their production and excitation function dates back to 1963. An overview of such attempts has been described below in nutshell.

\section{Production of Terbium Radionuclides by Light Charged Particle Activation}

Large numbers of neutron deficient clinically important radionuclides are produced in particle accelerators by light charged particle activation. The production cross sections of these radionuclides by light charged particle induced reactions are usually very high, which is not exactly true for terbium radionuclides.

The radionuclide ${ }^{149} \mathrm{~Tb}$ can be produced by ${ }^{152} \mathrm{Gd}(\mathrm{p}, 4 \mathrm{n})$ reaction, which has several distinct disadvantages. The most important is that the natural abundance of ${ }^{152} \mathrm{Gd}$ is only $0.2 \%$, and at present about a $30 \%$ level of enrichment is possible. Due to partial enrichment, the reaction channels from other Gd isotopes would open up and the final product would be contaminated by other longer-lived terbium and rare earth isotopes. Moreover, the radiochemical separation of $\mathrm{NCA}{ }^{149} \mathrm{~Tb}$ from neighboring bulk target or other co-produced radionuclides is a difficult task due to the similar chemical properties of the lanthanide elements.

Steyn et al. (33) had measured the cross sections of protoninduced reactions on ${ }^{152} \mathrm{Gd},{ }^{155} \mathrm{Gd}$, and ${ }^{159} \mathrm{~Tb}$ with emphasis on the production of clinically important terbium radionuclides in a new generation commercially available $70 \mathrm{MeV}$ cyclotron. The measured data was compared with different Monte Carlo simulation codes like ALICE. The authors have shown very high thick target yield of ${ }^{149} \mathrm{~Tb}$ and ${ }^{152} \mathrm{~Tb}$ is possible through the nuclear reactions of ${ }^{152} \mathrm{Gd}(\mathrm{p}, 4 \mathrm{n}){ }^{149} \mathrm{~Tb}$ and ${ }^{155} \mathrm{Gd}(\mathrm{p}, 4 \mathrm{n}){ }^{152} \mathrm{~Tb}$, respectively, provided highly enriched targets of ${ }^{152} \mathrm{Gd}$ and ${ }^{155} \mathrm{Gd}$ are used. It should be noted that close to $100 \%$ enrichment level of ${ }^{155} \mathrm{Gd}$ is possible. In the energy window of $66-30 \mathrm{MeV}$, production of $2,556 \mathrm{MBq} / \mu \mathrm{Ah}$ of ${ }^{149} \mathrm{~Tb}$ and $1,924 \mathrm{MBq} / \mu \mathrm{Ah}$ of ${ }^{152} \mathrm{~Tb}$ is achievable. However, due to the opening up of other reaction channels and also the impurity of other Gd isotopes in the target matrix, there will be $\mathrm{Dy}$ and $\mathrm{Tb}$ radionuclides contamination in both the ${ }^{149} \mathrm{~Tb}$ and ${ }^{152} \mathrm{~Tb}$ fractions. The indirect production route through ${ }^{159} \mathrm{~Tb}(\mathrm{p}, 5 \mathrm{n}){ }^{155} \mathrm{Dy}(\varepsilon)^{155} \mathrm{~Tb}$ can also provide high yields of ${ }^{155} \mathrm{~Tb}$. The advantage of this route 
is that ${ }^{159} \mathrm{~Tb}$ is the only naturally occurring stable isotope of terbium. The prominent disadvantage is that the product ${ }^{155} \mathrm{~Tb}$ is not in a no-carrier-added state, and always associated with bulk terbium. Also the yield would be contaminated by other dysprosium radioisotopes and their daughter products through ${ }^{159} \mathrm{~Tb}(\mathrm{p}, \mathrm{xn}){ }^{153,157,159} \mathrm{Dy}(\epsilon)^{153,157,159} \mathrm{~Tb}$ reactions. A highly efficient chemistry can exclude the dysprosium radionuclides but neither the bulk terbium nor the isotopic impurities of other terbium radionuclides.

On the contrary, Güray et al. (34) measured cross section of ${ }^{152} \mathrm{Gd}(\mathrm{p}, \mathrm{n})^{152} \mathrm{~Tb}$ reaction in a much lower energy range. The astrophysical gamma process was the motivation behind their experiment. Nevertheless, they observed about $\sim 101 \mathrm{mb}$ cross section at $8 \mathrm{MeV}$ for the above reaction. However, along with ${ }^{152} \mathrm{~Tb},{ }^{153} \mathrm{~Tb}$ would be co-produced via ${ }^{152} \mathrm{Gd}(\mathrm{p}, \gamma)^{153} \mathrm{~Tb}$ reaction with $\sim 4 \mathrm{mb}$ cross-section at $8 \mathrm{MeV}$. Another interesting experiment with comparatively low energy proton for production of ${ }^{152,155} \mathrm{~Tb}$ was carried out in Garching tandem accelerator (35). They produced ${ }^{152} \mathrm{~Tb}$ by irradiating a unique ion-implanted ${ }^{152} \mathrm{Gd}$ target (enrichment $>99 \%$ ) with 8 and $12 \mathrm{MeV}$ protons. The main purpose of this experiment was to determine activity ratios of potential co-produced radionuclides with respect to ${ }^{152} \mathrm{~Tb}$. They concluded that $12 \mathrm{MeV}$ proton energy is suitable for ${ }^{152} \mathrm{~Tb}$ production with $<1 \%$ contamination from ${ }^{153} \mathrm{~Tb}$. The radioisotopic purity of ${ }^{152} \mathrm{~Tb}$ can further be improved by playing with the thickness of the target and reducing the proton beam energy to 10 or $11 \mathrm{MeV}$.

Recently, Formento-Cavaier et al. (36) measured the production cross section and yield of ${ }^{149} \mathrm{~Tb}$ from the irradiation of a natural gadolinium target with a 70-58 $\mathrm{MeV}$ proton beam. They also evaluated the production cross section of other co-produced terbium radionuclides. However, they recorded only $7.1 \mathrm{mb}$ production cross section of ${ }^{149} \mathrm{~Tb}$ at 69.8 $\mathrm{MeV}$ projectile energy, produced through nat $\mathrm{Gd}(\mathrm{p}, \mathrm{x}){ }^{149} \mathrm{~Tb}$ reaction. At the same energy, the cross sections of other terbium radionuclides were measured as $31 \mathrm{mb}\left({ }^{150} \mathrm{~Tb}\right), 96 \mathrm{mb}\left({ }^{151} \mathrm{~Tb}\right)$, $114 \mathrm{mb}\left({ }^{152} \mathrm{~Tb}\right)$, and $124 \mathrm{mb}\left({ }^{153} \mathrm{~Tb}\right)$. Authors estimated that $\sim 40 \mathrm{MBq} / \mu \mathrm{Ah}$ integrated yield of ${ }^{149} \mathrm{~Tb}$ in $2.74 \mathrm{~mm}$ thick Gd target could be possible. But the desired radioisotope would be contaminated by the comparatively longer-lived $\mathrm{Tb}$ radioisotopes.

Similarly, deuteron-induced reactions were also studied for terbium radionuclide production. Exhaustive theoretical and experimental cross section data of ${ }^{n a t} \mathrm{Gd}(\mathrm{d}, \mathrm{xn}){ }^{151,152,153,154,155,156,160,161} \mathrm{~Tb}$ reactions in the projectile energy range $5-50 \mathrm{MeV}$ have been provided by Tárkányi et al. (37). Though considerably good cross section was obtained but the production of long-lived $\mathrm{Tb}$ isotopes could not be avoided along with the useful $\mathrm{Tb}$ radionuclides. Szelecsényi et al. (38) had re-measured excitation function for the ${ }^{\text {nat }} \mathrm{Gd}(\mathrm{d}, \mathrm{xn}){ }^{155} \mathrm{~Tb}$ and ${ }^{\text {nat }} \mathrm{Gd}(\mathrm{d}, \mathrm{xn}){ }^{161} \mathrm{~Tb}$ reactions from 4.2 to 21 $\mathrm{MeV}$ projectile energy. The cross-section of ${ }^{155} \mathrm{~Tb}$ is considerably high but the co-formation of long-lived $\mathrm{Tb}$ radioisotopes made the process unacceptable. Similarly, the amount of ${ }^{160} \mathrm{~Tb}$ would be higher than ${ }^{161} \mathrm{~Tb}$, therefore it is also not possible to produce only ${ }^{161} \mathrm{~Tb}$ by deuteron irradiation. Authors decisively concluded that low energy deuteron irradiation either on a natural or on a highly enriched Gd target would not produce isotopically pure NCA ${ }^{155} \mathrm{~Tb}$ or ${ }^{161} \mathrm{~Tb}$.

Duchemin et al. (39) measured the excitation function

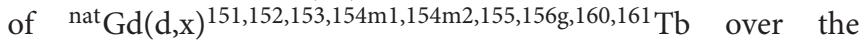
deuteron energy range 10-34 $\mathrm{MeV}$. Though the highest production cross section of ${ }^{155} \mathrm{~Tb}$ was observed at $24.6 \mathrm{MeV}$ deuteron beam, again it would be contaminated by other $\mathrm{Tb}$ and $\mathrm{Gd}$ radioisotopes.

Zagryadskii et al. (40) examined the efficacy of the production of ${ }^{149} \mathrm{~Tb}$ through ${ }^{151} \mathrm{Eu}\left({ }^{3} \mathrm{He}, 5 \mathrm{n}\right){ }^{149} \mathrm{~Tb}$ reaction in the energy range of $70-40 \mathrm{MeV}$. The thick target yield of ${ }^{149} \mathrm{~Tb}$ was $129 \mathrm{MBq} / \mu \mathrm{Ah}$, which is a considerably high yield for in vivo application. However, high radioisotopic impurities due to other exposed reaction channels were also observed. For example, ${ }^{3} \mathrm{He}$ bombardment on ${ }^{151} \mathrm{Eu}$ co-produced $75 \mathrm{MBq} / \mu \mathrm{Ah}{ }^{148} \mathrm{~Tb}, 335$ $\mathrm{MBq} / \mu \mathrm{Ah}{ }^{150} \mathrm{~Tb}, 845 \mathrm{MBq} / \mu \mathrm{Ah}{ }^{151} \mathrm{~Tb}$, and $98 \mathrm{MBq} / \mu \mathrm{Ah}{ }^{152} \mathrm{~Tb}$ along with the desired ${ }^{149} \mathrm{~Tb}$ radionuclide. Therefore, though a high production rate is observed for ${ }^{149} \mathrm{~Tb}$ or ${ }^{152} \mathrm{~Tb}$, unless the technology is developed to couple highly efficient isotope separation technique with commercial $70 \mathrm{MeV}$ cyclotron, the high yield is practically of no use. Moiseeva et al. (41) also reported the same route, i.e., production of ${ }^{149} \mathrm{~Tb}$ by irradiation of $97 \%$ enriched ${ }^{151} \mathrm{Eu}$ target with $70 \mathrm{MeV}^{3} \mathrm{He}$. They calculated about $38.7 \pm 7.7 \mathrm{MBq} / \mu \mathrm{Ah}$ thick target yield of ${ }^{149} \mathrm{~Tb}$ through ${ }^{151} \mathrm{Eu}\left({ }^{3} \mathrm{He}, 5 \mathrm{n}\right)$ reaction $\left(E_{\mathrm{p}}=70-30 \mathrm{MeV}\right)$. The yield would be quite good for successful administration into patient's body but unfortunately the yields of $150,151,152 \mathrm{~Tb}$ are much higher than ${ }^{149} \mathrm{~Tb}$. Therefore, possibility for production of radioisotopically pure ${ }^{149} \mathrm{~Tb}$ is ruled out.

In the case of $\alpha$-induced reactions, ${ }^{152} \mathrm{Gd}(\alpha, 7 \mathrm{n}){ }^{149} \mathrm{Dy}(\varepsilon)^{149} \mathrm{~Tb}$ reaction would give the highest yield, but the required projectile energy is of the order of $100 \mathrm{MeV}$, commonly unavailable in commercial cyclotrons. Moreover, the abundance of ${ }^{152} \mathrm{Gd}$ remains too low (42).

Light particle induced reactions on some particular isotopes like ${ }^{152} \mathrm{Gd}$ exhibits very high production cross sections of terbium radionuclides. However, natural abundance of these isotopes is very low, and sufficient technological advancement is required to increase the enrichment factors of these isotopes to a considerable level. Even if highly enriched targets are available, one cannot avoid production of other long-lived terbium radionuclides. To resolve this issue, commercial cyclotrons should be coupled with an isotope separator. Moreover, in some cases, as discussed above, higher projectile energy (e.g., $50 \mathrm{MeV}$ proton or $100 \mathrm{MeV} \alpha$ ) is required for high production yield of terbium radionuclides. Productions of terbium radionuclide in high quantity with high radioisotopic purity, especially production of ${ }^{149} \mathrm{~Tb}$ (the key radionuclide in terbium quadruplet) by light charged particle ( $\mathrm{p}, \mathrm{d},{ }^{3} \mathrm{He}$ or ${ }^{4} \mathrm{He}$ ) induced reactions is not possible to date. Therefore, scientists have also explored the possibility of terbium quadruplet production by heavy ion activation.

\section{Production of Terbium Radionuclides by Heavy Ion (HI) Activation}

Various nuclear reactions for heavy ion induced productions of terbium radioisotopes have been theoretically and experimentally 
explored for a long time. Amongst these ${ }^{141} \operatorname{Pr}\left({ }^{12} \mathrm{C}, \mathrm{xn}\right){ }^{149-151} \mathrm{~Tb}$, ${ }^{n a t} \mathrm{Nd}\left({ }^{12} \mathrm{C}, \mathrm{xn}\right){ }^{149,150-153} \mathrm{Dy}(\varepsilon)^{149,150-153} \mathrm{~Tb}$, ${ }^{142} \mathrm{Nd}\left({ }^{10} \mathrm{~B}, 3 \mathrm{n}\right){ }^{149} \mathrm{~Tb},{ }^{142} \mathrm{Nd}\left({ }^{11} \mathrm{~B}, 4 \mathrm{n}\right){ }^{149} \mathrm{~Tb},{ }^{144} \mathrm{Nd}\left({ }^{10} \mathrm{~B}, 5 \mathrm{n}\right){ }^{149} \mathrm{~Tb}$, ${ }^{140} \mathrm{Ce}\left({ }^{14} \mathrm{~N}, 5 \mathrm{n}\right){ }^{149} \mathrm{~Tb},{ }^{\text {nat }} \mathrm{Ce}\left({ }^{16} \mathrm{O}, \mathrm{xn}\right){ }^{149,151-153} \mathrm{Dy}(\varepsilon){ }^{149,151-153} \mathrm{~Tb}$, and ${ }^{139} \mathrm{La}\left({ }^{16} \mathrm{O}, \mathrm{xn}\right){ }^{149,151,152} \mathrm{~Tb}$ are noteworthy to mention.

Alexander and Simonoff (43) measured excitation functions of 12 heavy ion induced reactions that produce ${ }^{149} \mathrm{~Tb}$. They used different projectiles like ${ }^{10} \mathrm{~B},{ }^{11} \mathrm{~B},{ }^{12} \mathrm{C},{ }^{14} \mathrm{~N},{ }^{15} \mathrm{~N},{ }^{16} \mathrm{O}$, ${ }^{18} \mathrm{O}$, and ${ }^{19} \mathrm{~F}$ in combination with a variety of target isotopes from $\mathrm{Ba}$ to $\mathrm{Nd}$, among which ${ }^{141} \mathrm{Pr}$ is the only naturally abundant mononuclide target. Later, Kossakowski et al. (44) measured cross section of ${ }^{141} \operatorname{Pr}\left({ }^{12} \mathrm{C}, 4 \mathrm{n}\right){ }^{149} \mathrm{~Tb}$. Interestingly the cross section was two orders of magnitude higher than that of Alexander and Simonoff (43). This discrepancy and the importance of ${ }^{149} \mathrm{~Tb}$ prompted Maiti (45) to re-measure the excitation function of ${ }^{141} \operatorname{Pr}\left({ }^{12} \mathrm{C}, 4 \mathrm{n}\right){ }^{149} \mathrm{~Tb}$ reaction over a 79-44 MeV incident projectile energy range. The results of Maiti (45) were not encouraging for heavy ion assisted production of ${ }^{149} \mathrm{~Tb}$ and supported the low cross section values earlier reported by Alexander and Simonoff (43). Beyer et al. $(42,46)$ also attempted the production of ${ }^{149} \mathrm{~Tb}$ via ${ }^{141} \operatorname{Pr}\left({ }^{12} \mathrm{C}, 4 \mathrm{n}\right){ }^{149} \mathrm{~Tb}$ and ${ }^{142} \mathrm{Nd}\left({ }^{12} \mathrm{C}, 5 \mathrm{n}\right){ }^{149} \mathrm{Dy}(\varepsilon){ }^{149} \mathrm{~Tb}$ reactions at JINR Dubna. In the case of the $\mathrm{Nd}$ target, Beyer et al. (42) achieved a reasonably higher yield, $2.2 \mathrm{MBq} / \mu \mathrm{Ah}$ at the EOB. However, in this report the authors were silent about the co-produced radionuclides.

It is noteworthy to mention that many of the early attempts for heavy ion assisted production of terbium radionuclides were contributed from our group. For example, $\mathrm{CeO}_{2}$ target was irradiated with $80 \mathrm{MeV}{ }^{16} \mathrm{O}$, which produced ${ }^{151,152,153} \mathrm{Dy}$ and their daughter products ${ }^{151,152,153} \mathrm{~Tb}$ in the matrix (47). We also calculated theoretical excitation function of ${ }^{140} \mathrm{Ce}\left({ }^{16} \mathrm{O}, 4 \mathrm{n}\right){ }^{152} \mathrm{Dy}$, ${ }^{142} \mathrm{Ce}\left({ }^{16} \mathrm{O}, 6 \mathrm{n}\right){ }^{152}$ Dy along with ${ }^{140,142} \mathrm{Ce}\left({ }^{16} \mathrm{O}, \mathrm{xn}\right){ }^{151,153} \mathrm{Dy}$ by Monte Carlo simulation code PACE 2. Interestingly the production cross sections of ${ }^{151,153}$ Dy were found to be much higher than ${ }^{152} \mathrm{Dy}$. Studies on the production of terbium radionuclides were further continued by irradiating an $\mathrm{Nd}_{2} \mathrm{O}_{3}$ target with ${ }^{12} \mathrm{C}$, which produced ${ }^{150-153}$ Dy and their daughter products ${ }^{150-153} \mathrm{~Tb}$ radionuclides in the matrix (48). However, the yield of the radionuclides was low and not sufficient for in vivo applications. Due to the restrictions of BARC-TIFR pelletron (Mumbai, India), we could irradiate the $\mathrm{Nd}_{2} \mathrm{O}_{3}$ target with a maximum $83 \mathrm{MeV}{ }^{12} \mathrm{C}$ beam. Here also, excitation functions of ${ }^{142,144,146} \mathrm{Nd}\left({ }^{12} \mathrm{C}, \mathrm{xn}\right){ }^{150,151,152,153} \mathrm{Dy}$ reactions were calculated by PACE 2 code. It was found that the production cross section of ${ }^{152} \mathrm{Dy}$ is comparable with those of ${ }^{150,151,153} \mathrm{Dy}$ and therefore ${ }^{152} \mathrm{~Tb}$ (decay product of ${ }^{152}$ Dy) would always be contaminated by longer-lived isotopes of $\mathrm{Dy}$ and $\mathrm{Tb}$. We have also attempted production of ${ }^{151,152} \mathrm{~Tb}$ by ${ }^{16} \mathrm{O}$ irradiation on $\mathrm{La}_{2} \mathrm{O}_{3}$ target (49). The advantage of this method is that terbium radionuclides are directly produced through ${ }^{139} \mathrm{La}\left({ }^{16} \mathrm{O}, \mathrm{xn}\right){ }^{151,152} \mathrm{~Tb}$ reaction, not through the decay of dysprosium radionuclides like earlier examples.

In Table 3 we have provided a concise picture of various attempts of terbium radionuclides production by light and heavy ion induced reactions.

\section{Production of Terbium Radionuclides by Spallation Reaction}

The other option left for the production of terbium radionuclides with high purity and in high quantity is spallation induced reactions. One of the major constraints of spallation reaction is that such high energy facilities are limited to only few centers worldwide. Nevertheless, a glimpse of vibrant research carried out in such advanced centers to produce terbium radionuclides has been given below.

Literature is available on the production of ${ }^{149} \mathrm{~Tb}$ by spallation reaction even in 1966, though the aim of the experiment was something else. Franz and Friedlander (53) measured the production cross section of ${ }^{149} \mathrm{~Tb}$ from 0.6 to $30 \mathrm{GeV}$ proton induced reaction on $\mathrm{Au}$ target. The reported cross sections were rather low, e.g., for $1.4 \mathrm{GeV}$ proton beam, the production cross section of ${ }^{148} \mathrm{~Tb}$ was only about $10 \mathrm{mb}$. Heydegger and Van Ginneken (54) re-measured the production cross section of ${ }^{149} \mathrm{~Tb}$ produced from 0.2 to $0.4 \mathrm{GeV}$ proton induced reaction on gold target. They reported a still lower cross section, $\sim 5 \mu \mathrm{b}$ at 0.4 $\mathrm{GeV}$ energy.

The CERN-ISOLDE has the lead role in research on production of terbium quadruplet radioisotopes by the impact of high energy proton. Allen et al. (55) irradiated a Ta foil target by $1 \mathrm{GeV}$ protons at CERN proton accelerator in order to produce radio-lanthanides by spallation reaction. The products of $A=$ 152 were collected by an online mass separator at the ISOLDE on high purity $\mathrm{Al}$ catcher foil, and later on, they detected ${ }^{152} \mathrm{~Tb}$ in the catcher foil in considerable amounts. Beyer et al. (42) irradiated a thick Ta foil $\left(112 \mathrm{~g} \mathrm{~cm}^{-2}\right)$ by $1-2 \mu \mathrm{A}$ integrated beam current, $1.4 \mathrm{GeV}$ proton beam from the CERN PS booster and obtained about $500 \mathrm{MBq}{ }^{149} \mathrm{~Tb}$ at the end of collection (EOC), after 4-8 $\mathrm{h}$ bombardment. Later on, isobars of 149 mass numbers were collected using the ISOLDE facility at CERN into a thin layer of $\mathrm{KNO}_{3}$, which was molten on Al-backings. In another experiment (31), a Ta-foil implanted into thin $\mathrm{KNO}_{3}$ layer on an aluminum holder was irradiated with $1.4 \mathrm{GeV}$ protons at the CERN-ISOLDE facility. In both the experiments, radiochemical separation of the desired isotope was required, which has been described in section Chemical Separation of Terbium Radionuclides From the Target Matrix.

Recently, Verhoeven et al. (56) measured the spallation cross sections for the production of ${ }^{149} \mathrm{~Tb}$ from a tantalum target at different proton energies from 0.3 to $1.7 \mathrm{GeV}$. They observed that the highest production cross section of ${ }^{149} \mathrm{~Tb}$ from a Ta target is around 1.1 and $1.3 \mathrm{GeV}$ energy range. From this data they concluded that the operating energy at CERN-ISOLDE $(1.4 \mathrm{GeV})$ is not optimum for ${ }^{149} \mathrm{~Tb}$ production. A lower proton energy (1.3 $\mathrm{GeV}$ ) would give a much higher yield of ${ }^{149} \mathrm{~Tb}$.

In the CERN-MEDICIS facility, the terbium radionuclides, ${ }^{149} \mathrm{~Tb},{ }^{152} \mathrm{~Tb}$, and ${ }^{155} \mathrm{~Tb}$ are produced in $1.4 \mathrm{GeV}$ proton induced spallation on Ta-Re targets placed behind the ISOLDE-HRS target. Typical irradiation lasts for $12-16 \mathrm{~h}$. About $38 \mathrm{GBq}{ }^{149} \mathrm{~Tb}$, $37 \mathrm{GBq}{ }^{152} \mathrm{~Tb}$, and $5.3 \mathrm{GBq}{ }^{155} \mathrm{~Tb}$ in target activity can be produced. However, the extraction efficiency is $\sim 1 \%$, with a wide scope for improvement. The ${ }^{161} \mathrm{~Tb}$ is produced in $\mathrm{UC}_{\mathrm{x}}-\mathrm{Re}$ target with in-target activity of $19 \mathrm{MBq}$ and $1 \%$ extraction efficiency. 
TABLE 3 | Available production cross section data of terbium radionuclides.

\begin{tabular}{|c|c|c|c|c|}
\hline Nuclear reaction & Projectile energy, MeV & Cross section $\left(\sigma_{\max }\right), \mathbf{m b}$ & Comment & References \\
\hline${ }^{152} \mathrm{Gd}(\mathrm{p}, 4 \mathrm{n}){ }^{149} \mathrm{~Tb}$ & 41.31 & 248 & & (33) \\
\hline${ }^{155} \mathrm{Gd}(\mathrm{p}, 4 \mathrm{n})^{152} \mathrm{~Tb}$ & 48.2 & 821 & & \\
\hline${ }^{\text {nat }} \mathrm{Gd}(\mathrm{p}, \mathrm{x})^{149} \mathrm{~Tb}$ & 69.8 & 7 & 150,151,153 Tb will also be produced in considerable amount & $(36)$ \\
\hline${ }^{\text {nat }} \mathrm{Gd}(\mathrm{p}, \mathrm{x})^{152} \mathrm{~Tb}$ & & 114 & & \\
\hline${ }^{152} \mathrm{Gd}(\mathrm{p}, \mathrm{n})^{152} \mathrm{~Tb}$ & 8 & 101 & ${ }^{153} \mathrm{~Tb}$ is co-produced with $4 \mathrm{mb}$ cross section & $(34)$ \\
\hline${ }^{159} \mathrm{~Tb}(\mathrm{p}, \mathrm{n})^{152} \mathrm{~Tb}$ & 97 & 244 & & $(50)$ \\
\hline \multirow[t]{3}{*}{${ }^{\text {nat }} \mathrm{Gd}(\mathrm{d}, \mathrm{x})^{152,155,161} \mathrm{~Tb}$} & 49.2 & ${ }^{152} \mathrm{~Tb}=98.2$ & $151,154,156,160 \mathrm{~Tb}$ isotopes are co-produced & $(37)$ \\
\hline & 42.1 & ${ }^{155} \mathrm{~Tb}=376$ & & \\
\hline & 10.9 & ${ }^{161} \mathrm{~Tb}=234$ & & \\
\hline \multirow[t]{2}{*}{${ }^{\text {nat }} \mathrm{Gd}(\mathrm{d}, \mathrm{x})^{152,161} \mathrm{~Tb}$} & 21.1 & ${ }^{155} \mathrm{~Tb}=269$ & $156,160 \mathrm{~Tb}$ isotopes are co-produced & $(38)$ \\
\hline & 9.6 & ${ }^{161} \mathrm{~Tb}=39$ & & \\
\hline \multirow[t]{2}{*}{${ }^{\text {nat }} \mathrm{Gd}(\mathrm{d}, \mathrm{x})^{152,155} \mathrm{~Tb}$} & 33.34 & ${ }^{152} \mathrm{~Tb}=14.4$ & $\begin{array}{l}153,154 \mathrm{~m} 1,154 \mathrm{~m} 2,156 \mathrm{~g}, 160 \mathrm{~Tb} \text { and }{ }^{153,159} \mathrm{Gd} \text { isotopes are co-produced } \\
\text { in high quantity }\end{array}$ & (39) \\
\hline & 24.56 & ${ }^{155} \mathrm{~Tb}=317.7$ & & \\
\hline${ }^{\text {nat }} \mathrm{Gd}(\mathrm{a}, \mathrm{x})^{155} \mathrm{~Tb}$ & 73.4 & 304.43 & & $(51)$ \\
\hline${ }^{141} \operatorname{Pr}\left({ }^{12} \mathrm{C}, \mathrm{xn}\right){ }^{149} \mathrm{~Tb}$ & 77.4 & 408 & & $(44)$ \\
\hline${ }^{141} \operatorname{Pr}\left({ }^{14} \mathrm{~N}, \mathrm{p} 5 \mathrm{n}\right){ }^{149} \mathrm{~Tb}$ & 101 & 220 & & \\
\hline \multirow[t]{3}{*}{${ }^{141} \operatorname{Pr}\left({ }^{12} \mathrm{C}, \mathrm{xn}\right){ }^{149-151} \mathrm{~Tb}$} & 62.1 & ${ }^{149} \mathrm{~Tb}=27.3$ & Very high production cross section of ${ }^{149} \mathrm{Gd}$ & $(45)$ \\
\hline & 52.9 & ${ }^{150} \mathrm{~Tb}=36.4$ & & \\
\hline & 54.1 & ${ }^{151} \mathrm{~Tb}=32.7$ & & \\
\hline${ }^{152} \mathrm{Sm}\left({ }^{7} \mathrm{Li}, 4 \mathrm{n}\right){ }^{155} \mathrm{~Tb}$ & 38 & 669 & & (52) \\
\hline
\end{tabular}

${ }^{161} \mathrm{~Tb}$ can also be produced after bombardment of neutrons on highly enriched ${ }^{160} \mathrm{Gd}$ targets at spallation neutron source (SINQ) of Paul Scherrer Institute (PSI), Switzerland or at a highflux nuclear reactor at Laue-Langevin (ILL) situated in France (57). The SPES-ISOLPHARM facility in Italy is also planning to produce ${ }^{152} \mathrm{~Tb},{ }^{155} \mathrm{~Tb},{ }^{156} \mathrm{~Tb},{ }^{161} \mathrm{~Tb}$ radioisotopes by high flux protons bombardment on Gd targets (58).

In a recent experiment, our group had irradiated lead bismuth eutectic (LBE) targets at CERN-ISOLDE by a $1.4 \mathrm{GeV}$ proton beam. The LBE targets have been proposed as converter targets and would be used worldwide in next-generation RIB facilities. We have assessed all the radionuclides produced by the interaction of $1.4 \mathrm{GeV}$ proton beam in the LBE matrix and found numbers of clinically important radionuclides including some of the radionuclides of the Swiss-knife family. It is estimated that about $4.5 \mathrm{MBq} / \mu A h^{149} \mathrm{~Tb}$ and ${ }^{151} \mathrm{~Tb}$ will be produced in $50 \mathrm{~mm}$ long and $6 \mathrm{~mm}$ diameter LBE targets, which is a considerable amount for in vivo applications if it can be separated using ISOL or similar facilities (59).

\section{CHEMICAL SEPARATION OF TERBIUM RADIONUCLIDES FROM THE TARGET MATRIX}

For in vivo application, any radionuclide should be free from the target matrix and chemistry has an important role. There are only a few reports available in literature related to the radiochemical separations of terbium radionuclides. Earlier, production of NCA ${ }^{161} \mathrm{~Tb}$ was attempted by Subhodaya et al. (60) by the neutron activation of natural gadolinium, and subsequent $\beta$ decay of ${ }^{161} \mathrm{Gd}$ to ${ }^{161} \mathrm{~Tb}$. The $\mathrm{NCA}{ }^{161} \mathrm{~Tb}$ was separated from gadolinium target by Dowex 50 resin using $\alpha$-hydroxybutyric acid (HIBA) at $\mathrm{pH} 4.4$ as eluent. All the lanthanide elements have similar properties. The separation is even difficult and a colossal task when no-carrier-added lanthanide has to be separated from the adjacent bulk amount lanthanide. Though Subhodaya et al. (60) reported considerable amounts of separation of ${ }^{161} \mathrm{~Tb}$ from the bulk gadolinium target, they could not achieve enough purity required for clinical application.

Liquid Liquid extraction (LLX) technique was utilized to separate ${ }^{151,152,153} \mathrm{Dy},{ }^{151,152,153} \mathrm{~Tb}$ from the ${ }^{16} \mathrm{O}$ irradiated ceric oxide target (47). The irradiated target was dissolved in a mixture of conc. $\mathrm{HNO}_{3}$ and $\mathrm{H}_{2} \mathrm{SO}_{4}$ acid, evaporated to dryness, and finally taken into $10^{-3} \mathrm{M} \mathrm{HCl}$ medium. The liquid cation exchanger, di-(2-ethylhexyl)phosphoric acid (HDEHP) dissolved in cyclohexane was used as extractant. An excellent separation was achieved where the organic phase contained only $151,152,153 \mathrm{~Tb}(\sim 90 \%$ chemical yield) without any contamination of co-produced Dy radionuclides or bulk Ce target. Similarly, an attempt was made to separate $\mathrm{NCA}{ }^{150-153} \mathrm{~Tb}$ radionuclides from ${ }^{12} \mathrm{C}$ irradiated $\mathrm{Nd}_{2} \mathrm{O}_{3}$ target and the co-produced ${ }^{150-153} \mathrm{Dy}$ radionuclides (48). The same reagent, i.e., HDEHP was used and ${ }^{150-153} \mathrm{~Tb}$ could be separated with high radiochemical purity.

As discussed in section Production of terbium radionuclides by spallation reaction, Beyer et al. (42) bombarded a Ta target with a $1.4 \mathrm{GeV}$ proton beam for $4-8 \mathrm{~h}$ and collected the $A=$ 149 isobars. Since the half-life of ${ }^{149} \mathrm{~Tb}$ is comparable to the time of collection, the ${ }^{149} \mathrm{~Tb}$ was contaminated by its decay products, ${ }^{149} \mathrm{Gd}$ and ${ }^{149} \mathrm{Eu}$. Moreover, ${ }^{133} \mathrm{Ce}$ and ${ }^{133} \mathrm{La}$ in the form of 
TABLE 4 | Radiochemical separation of no-carrier-added terbium radionuclides.

\begin{tabular}{|c|c|c|c|}
\hline Nuclear reaction & Radiochemical separation & Separation factors (S) & References \\
\hline $\mathrm{Gd}(\mathrm{n}, \gamma)^{161} \mathrm{Gd}(\varepsilon)^{161} \mathrm{~Tb}$ & $\begin{array}{l}\text { Extraction using DOWEX } 50 \text { resin, and } \alpha \text { - HIBA } \\
\text { as. eluent at } \mathrm{pH} 4.4\end{array}$ & & $(60)$ \\
\hline nat $\left.\mathrm{Nd}\left({ }^{12} \mathrm{C}, \mathrm{xn}\right)\right)^{150-153} \mathrm{Dy}(\varepsilon)^{150-153} \mathrm{~Tb}$ & LLX: HDEHP/cyclohexane and $\mathrm{HCl}$ & $\begin{array}{c}S_{\mathrm{Tb} / \mathrm{Nd}}=100 \\
S_{\mathrm{Dy} / \mathrm{Nd}}=390 \\
S_{\mathrm{Tb} / \mathrm{Dy}}=38\end{array}$ & $(48)$ \\
\hline$\left.{ }^{\text {nat }} \mathrm{Ce}\left({ }^{16} \mathrm{O}, \mathrm{xn}\right)\right)^{151-153} \mathrm{Dy}(\varepsilon)^{151-153} \mathrm{~Tb}$ & LLX: HDEHP/cyclohexane and $\mathrm{HCl}$ & $\begin{array}{c}S_{\mathrm{Tb} / \mathrm{Ce}}=657 \\
S_{\mathrm{Dy} / \mathrm{Ce}}=41,157 \\
S_{\mathrm{Tb} / \mathrm{Dy}}=38\end{array}$ & $(47)$ \\
\hline${ }^{141} \operatorname{Pr}\left({ }^{12} \mathrm{C}, \mathrm{xn}\right){ }^{149-151} \mathrm{~Tb}$ & LLX: HDEHP/cyclohexane and $\mathrm{HCl}$ & $\begin{array}{c}S_{\mathrm{Tb} / \mathrm{Pr}}=470,000 \\
S_{\mathrm{Gd} / \mathrm{Pr}}=394 \\
S_{\mathrm{Tb} / \mathrm{Gd}}=52,000\end{array}$ & (63) \\
\hline${ }^{139} \mathrm{La}\left({ }^{16} \mathrm{O}, \mathrm{xn}\right){ }^{149,151,152} \mathrm{~Tb}$ & LLX: HDEHP/cyclohexane and $\mathrm{HCl}$ & $S_{\mathrm{Tb} / \mathrm{La}}=816$ & $(49)$ \\
\hline $\begin{array}{l}\text { Proton induced spallation on Ta target, } \\
\text { followed by collection of } \mathrm{A}=149 \text { fraction by } \\
\text { ISOL which contained }{ }^{149} \mathrm{~Tb},{ }^{149} \mathrm{Gd},{ }^{149} \mathrm{Eu} \text {, } \\
{ }^{133} \mathrm{CeO}^{+},{ }^{133} \mathrm{LaO}^{+}\end{array}$ & $\begin{array}{l}\text { Adsorption in cation exchange; AMINEX-A5, } \\
\text { followed by elution with } \alpha \text {-HIBA }\end{array}$ & $\begin{array}{l}{ }^{149} \mathrm{~Tb} \text { was eluted first without contamination } \\
\text { from other radionuclides }\end{array}$ & $(42)$ \\
\hline${ }^{142} \mathrm{Nd}\left({ }^{12} \mathrm{C}, 5 \mathrm{n}\right){ }^{149} \mathrm{Dy}(\varepsilon){ }^{149} \mathrm{~Tb}$ & Tb, Gd separation, elution with $\alpha$-HIBA & & $(64,65)$ \\
\hline Separation study of isobaric ${ }^{149} \mathrm{~Tb}$ and ${ }^{133} \mathrm{Ce}$ & $\begin{array}{l}\text { Extraction chromatography using UTEVA, } \\
\text { TEVA, TK-100, AG-1 resin, } 8 \mathrm{M} \mathrm{HNO}_{3}\end{array}$ & $\begin{array}{l}{ }^{149} \mathrm{~Tb} \text { was eluted first, later Ce was eluted by } \\
\qquad \mathrm{HCl}\end{array}$ & $(61)$ \\
\hline $\mathrm{Gd}(\mathrm{n}, \gamma)^{161} \mathrm{Gd}(\varepsilon)^{161} \mathrm{~Tb}$ & $\begin{array}{l}\text { Extraction chromatography using } \mathrm{LN} \text { resin, } \\
\qquad 0.8 \mathrm{M} \text { and } 3 \mathrm{M} \mathrm{HNO}_{3}\end{array}$ & & $(62,66)$ \\
\hline
\end{tabular}

pseudo-isobaric ions, ${ }^{133} \mathrm{CeO}^{+}$and ${ }^{133} \mathrm{LaO}^{+}$, also contaminated the ${ }^{149} \mathrm{~Tb}$ fraction. Therefore, radiochemical separation was mandatory to get pure ${ }^{149} \mathrm{~Tb}$. Beyer et al. (42) separated the radio-lanthanides by cation exchange chromatography with Aminex A5 resin. The radio-lanthanides were eluted with $\alpha$ hydroxyisobutyric acid ( $\alpha$-HIBA) at $\mathrm{pH} 5.0 .{ }^{149} \mathrm{~Tb}$ was eluted first followed by ${ }^{149} \mathrm{Gd}$ and ${ }^{149} \mathrm{Eu}$. The pseudo-isobars ${ }^{133} \mathrm{CeO}^{+}$ and ${ }^{133} \mathrm{LaO}^{+}$were eluted at the end. A similar study on the chemical separation of ${ }^{155} \mathrm{~Tb}$ from pseudo-isobaric ${ }^{139} \mathrm{Ce}^{16} \mathrm{O}$ was reported by Webster et al. (61). In this study, sodium bromate was used to oxidize $\mathrm{Ce}(\mathrm{II})$ to $\mathrm{Ce}(\mathrm{IV})$. Pre-packed commercial resins like UTEVA, TEVA, TK100, and AG1 were used for extraction chromatographic studies. $8 \mathrm{M} \mathrm{HNO} 3$ could elute ${ }^{155} \mathrm{~Tb}$ without contamination from $\mathrm{Ce}$, which was later eluted by $0.1 \mathrm{M} \mathrm{HCl}$.

Aziz and Artha (62) reported the separation of ${ }^{161} \mathrm{~Tb}$ from bulk Gd target by extraction chromatography using LN resin. ${ }^{161} \mathrm{~Tb}$ was produced by thermal neutron irradiation of natural $\mathrm{Gd}_{2} \mathrm{O}_{3}$. The bulk $\mathrm{Gd}$ was eluted first by $0.8 \mathrm{M} \mathrm{HNO}_{3}$ followed by elution of ${ }^{161} \mathrm{~Tb}$ by $3 \mathrm{M} \mathrm{HNO}_{3}$. Authors reported that about $70 \%$ of ${ }^{161} \mathrm{~Tb}$ could be recovered with $>99 \%$ radionuclide purity.

Maiti et al. (63) irradiated natural praseodymium target with $72 \mathrm{MeV}^{12} \mathrm{C}$ beam and produced NCA ${ }^{149,150,151} \mathrm{~Tb}$ radionuclides along with ${ }^{149} \mathrm{Gd}$ in the matrix. After production, the NCA terbium radionuclides were separated from the target by LLX using HDEHP/cyclohexane as liquid cation exchanger. The terbium radionuclides, ${ }^{151,152} \mathrm{~Tb}$ were extracted in the organic phase and was back extracted by DTPA. As high as a $10^{5}$ separation factor was achieved between bulk $\operatorname{Pr}$ and NCA $\mathrm{Tb}$ radionuclides (63).
Therefore, the role of chemical separation cannot be ignored even in the presence of the ISOL technique. In Table 4 we have provided the list of radioanalytical chemistry developed so far for separation of terbium radionuclides.

\section{CONCLUSION}

The use of terbium radionuclides for TAT, to deliver very small radiation doses exactly where they are needed to avoid destroying the surrounding healthy tissues, would be a great jump in the field of nuclear medicine. However, the research with the theranostics terbium quadruplet radionuclides are limited mainly in and around Geneva city. Only a handful numbers of preclinical trials have been conducted. Many more such studies are required before their direct administration to the human body for therapy or diagnosis. The main constraint is the limited scope for production of the terbium radionuclides in sufficient amounts due to the costs of highly enriched targets, low reaction cross section, radioactive impurities, presence of non-radioactive isotope, etc. Isotope separation on-line (ISOL) has become the much-sorted accelerator technology at present and is also the future to solve the riddle of terbium isotope production. Following the CERN's success, many mega facilities for RIB research, like ISAC, Canada; ISOL@MYRRHA, Belgium; J-PARC ISOL, Japan; ISOLPHARM, Italy, etc., have now dedicated some of their programs to medical research and the production of isotopes. In fact, dedication of research toward the direct benefit of mankind will also help these centers to sustain the research on fundamental science. However, one has to keep in mind that the research facilities can only help to start medical programs 
to make the proof of concept. It is important that the industry should take over at some points to consolidate production. It is also necessary to develop techniques that are affordable and easy to handle.

\section{AUTHOR CONTRIBUTIONS}

NN and SL: conceptualization, primary literature search, writing of the drafts, and corrections. All authors contributed to the article and approved the submitted version.

\section{REFERENCES}

1. Early PJ. Use of diagnostic radionuclides in medicine. Health Phys. (1995) 69:649-61. doi: 10.1097/00004032-199511000-00003

2. Nagarajah J, Janssen M, Hetkamp P, Jentzen W. Iodine symporter targeting with 124I/131I theranostics. J Nucl Med. (2017) 58:34S-8S. doi: 10.2967/jnumed.116.186866

3. Ahn BC. Personalized medicine based on theranostic radioiodine molecular imaging for differentiated thyroid cancer. BioMed Res Int. (2016) 2016:1680464. doi: 10.1155/2016/1680464

4. Schottelius M, Šimecek J, Hoffmann F, Willibald M, Schwaiger M, Wester HJ. Twins in spirit-episode I: comparative preclinical evaluation of [68Ga]DOTATATE and [68Ga]HA- DOTATATE. EJNMMI Res. (2015) 5:22. doi: 10.1186/s13550-015-0099-X

5. Lopci E, Chiti A, Castellani MR, Pepe G, Antunovic L, Fanti S, et al. Matched pairs dosimetry: I-124/I-131 metaiodobenzylguanidine and I-124/I131 and Y-86/Y-90 antibodies. Eur J Nucl Med Mol Imaging. (2011) 38:S2840. doi: 10.1007/s00259-011-1772-6

6. Notni J, Wester HJ. Re-thinking the role of radiometal isotopes: towards a future concept for theranostic radiopharmaceuticals. J Labelled Comp Radiopharm. (2018) 61:141-53. doi: 10.1002/jlcr.3582

7. Qaim SM, Scholten B, Neumaier B. New developments in the production of theranostic pairs of radionuclides. J Radioanal Nucl Chem. (2018) 318:1493509. doi: 10.1007/s10967-018-6238-x

8. Naskar N, Lahiri S. Separation of no-carrier-added 71,72As from $46 \mathrm{MeV}$ alpha particle irradiated gallium oxide target. Radiochim Acta. (2021) 109:389-95. doi: 10.1515/ract-2020-0120

9. Jalilian AR. An overview on Ga-68 radiopharmaceuticals for positron emission tomography applications, Iran. J Nucl Med. (2016) 24:1-10.

10. Drude N, Tienken L, Mottaghy FM. Theranostic and nanotheranostic probes in nuclear medicine. Methods. (2017) 130:14-22. doi: 10.1016/j.ymeth.2017.07.004

11. Couturier O, Supiot S, Degraef-Mougin M, Faivre-Chauvet A, Carlier T, Chatal JF. Cancer radioimmunotherapy with alpha-emitting nuclides. Eur J Nucl Med Mol Imaging. (2005) 32:601-14. doi: 10.1007/s00259-005-1803-2

12. Feinendegen LE. Biological damage from the auger effect, possible benefits. Radiat Environ Biophys. (1975) 12:85-99. doi: 10.1007/BF01328970

13. Formento-Cavaier R, Haddad F, Sounalet T, Stora T, Zahi I. Terbium radionuclides for theranostics applications: a focus on MEDICIS-PROMED. Phys Procedia. (2017) 90:157-63. doi: 10.1016/j.phpro.2017.09.053

14. Kim JS. Combination radioimmunotherapy approaches and quantification of immuno-PET. Nucl Med Mol Imaging. (2016) 50:104-11. doi: 10.1007/s13139-015-0392-7

15. Kassis AI. The amazing world of auger electrons. Int J Radiat Biol. (2004) 80:789-803. doi: 10.1080/09553000400017663

16. Allen BJ, Blagojevic N. Alpha-and beta-emitting radiolanthanides in targeted cancer therapy: the potential role of terbium-149. Nucl Med Commun. (1996) 17:40-7. doi: 10.1097/00006231-199601000-00008

17. Dillehay LE. A model of cell-killing by low dose rate radiation including repair of sublethal, G2 block, and cell division. Radiat Res. (1990) 124:2017. doi: $10.2307 / 3577867$

18. Franken NA, Hovingh S, Ten Cate R, Krawczyk P, Stap J,Hoebe R, et al. Relative biological effectiveness of high linear energy transfer $\alpha$-particles for

\section{FUNDING}

Publication fee supported from European Commission's Horizon 2020 Programme under contract number 642889 MEDICISPROMED is acknowledged.

\section{ACKNOWLEDGMENTS}

Authors are thankful to Drs. Thierry Stora and John O. Prior for their kind support.

the induction of DNA-double-strand breaks, chromosome aberrations and reproductive cell death in SW-1573 lung tumour cells. Oncol Rep. (2012) 27:769-74. doi: 10.3892/or.2011.1604

19. Gadbois DM, Crissman HA, Nastasi A, Habbersett R, Wang SK,Chen $\mathrm{D}$,et al. Alterations in the progression of cells through the cell cycle after exposure to alpha particles or gamma rays. Radiat Res. (1996) 146:41424. doi: $10.2307 / 3579303$

20. Sartor O, Maalouf BN, Hauck CR, Macklis RM. Targeted use of alpha particles: current status in cancer therapeutics. J Nucl Med Radiat Ther. (2012) 3:136. doi: 10.4172/2155-9619.1000136

21. https://www.nndc.bnl.gov/nudat2/ (accessed March 30, 2021).

22. Nayak D, Lahiri S. Application of radioisotopes in the field of nuclear medicine part I: lanthanide series elements. J Radioanal Nucl Chem. (1999) 242:42332. doi: 10.1007/BF02345573

23. CERN Bulletin, Issue no 14-15 (2012). Available online at: https://cds.cern.ch/ journal/CERNBulletin/2012/14/News\%20Articles/1434420

24. Stora T. Isotopes for precision medicine. CERN Courier. (2018) 58:29.

25. Müller C, Zhernosekov K, Koester U, Johnston K, Dorrer H, Hohn A, et al. A unique matched quadruplet of terbium radioisotopes for PET and SPECT and for $\alpha$ and $\beta$-radionuclide therapy: an in vivo proof-of-concept study with a new receptor-targeted folate derivative. J Nucl Med. (2012) 53:1951-9. doi: 10.2967/jnumed.112.107540

26. Beyer GJ, Miederer M, Vranjes-Duric S, Comor JJ, Kunzi G, Hartley O, et al. Targeted alpha therapy in vivo: direct evidence for single cancer cell kill using 149Tb-rituximab. Eur J Nucl Med Mol Imaging. (2004) 31:557. doi: 10.1007/s00259-003-1413-9

27. Nedrow JR, Anderson CJ. Emerging radiometals for PET imaging. Encyclopedia Inorg Bioinorg Chem. (2011) 111. doi: 10.1002/9781119951438.eibc2447

28. Beyer, G. Radioactive ion beams for biomedical research and nuclear medical application. Hyperfine Interact. (2000) 129:529-53. doi: 10.1023/A:1012670018533

29. Müller C, Umbricht CA, Gracheva N, Tschan VJ, Pellegrini G, Bernhardt $\mathrm{P}$, et al. Terbium-161 for PSMA-targeted radionuclide therapy of prostate cancer. Eur J Nucl Med Mol Imaging. (2019) 46:1919-30. doi: 10.1007/s00259-019-04345-0

30. Lehenberger S, Barkhausen C, Cohrs S, Fischer E, Grünberg J, Hohn A, et al. The low-energy $\beta$ - and electron emitter $161 \mathrm{~Tb}$ as an alternative to 177Lu for targeted radionuclide therapy. Nucl Med Biol. (2011) 38:91724. doi: 10.1016/j.nucmedbio.2011.02.007

31. Baum RP, Singh A, Benešová $M$, Vermeulen $C$, Gnesin S, Köster U, et al. Clinical evaluation of the radiolanthanide terbium-152: first-inhuman PET/CT with 152Tb-DOTATOC. Dalton Transact. (2017) 46:1463846. doi: 10.1039/C7DT01936J

32. Champion C, Quinto MA, Morgat C, Zanotti-Fregonara P, Hindie E. Comparison between three promising $\beta$-emitting radionuclides, $67 \mathrm{Cu}, 47 \mathrm{Sc}$ and $161 \mathrm{~Tb}$, with emphasis on doses delivered to minimal residual disease. Theranostics. (2016) 6:1611-8. doi: 10.7150/thno.15132

33. Steyn GF, Vermeulen C, Szelecsenyi F, Kovvacs Z, Hohn A, Van Der Meulen et al. Cross-sections of proton-induced reactions on $152 \mathrm{Gd}, 155 \mathrm{Gd}$ and $159 \mathrm{~Tb}$ with emphasis on the production of selected $\mathrm{Tb}$ radionuclides. Nucl Inst Methods Phys Res Sect B Beam Interact Mater Atoms. (2014) 319:12840. doi: 10.1016/j.nimb.2013.11.013 
34. Güray RT, Özkan N, Yalçin C, Rauscher T, Gyürky GY, Farkas J, et al. Measurements of $152 \mathrm{Gd}(\mathrm{p}, \gamma) 153 \mathrm{~Tb}$ and $152 \mathrm{Gd}(\mathrm{p}, \mathrm{n}) 152 \mathrm{~Tb}$ reaction cross sections for the astrophysical $\gamma$ process. Phys Rev C. (2015) 91:055809. doi: 10.1103/PhysRevC.91.055809

35. Köster U, Assmann W, Bacri CO, Faestermann T, Garrett P, Gernhäuser $\mathrm{R}$, et al. Electromagnetic isotope separation of gadolinium isotopes for the production of 152,155Tb for radiopharmaceutical applications. Nucl Inst Meth Phys Res B. (2020) 463:111-4. doi: 10.1016/j.nimb.2019.07.017

36. Formento-Cavaier R, Haddad F, Alliot C, Sounalet T, Zahi I. New excitation functions for proton induced reactions on natural gadolinium up to $70 \mathrm{MeV}$ with focus on $149 \mathrm{~Tb}$ production. Nucl Inst Methods Phys Res Sect B Beam Interact Mater Atoms. (2020) 478:174-81. doi: 10.1016/j.nimb.2020.06.029

37. Tárkányi F, Takács S, Ditrói F, Csikai J, Hermanne A, Ignatyuk AV. Activation cross-sections of deuteron induced reactions on. natGd up to $50 \mathrm{MeV}$. Appl Radiat Isot. (2014) 83:25-35. doi: 10.1016/j.apradiso.2013.10.010

38. Szelecsényi F, Kovács Z, Nagatsu K, Zhang MR, Suzuki K. Investigation of deuteron-induced reactions on natGd up to $30 \mathrm{MeV}$ : possibility of production of medically relevant $155 \mathrm{~Tb}$ and $161 \mathrm{~Tb}$ radioisotopes. J Radioanal Nucl Chem. (2016) 307:1877-81. doi: 10.1007/s10967-015-4528-0

39. Duchemin C, Guertin A, Haddad F, Michel N, Métivier V. Deuteron induced $\mathrm{Tb}-155$ production, a theranostic isotope for SPECT imaging and auger therapy. Appl Radiat Isot. (2016) 118:281-9. doi: 10.1016/j.apradiso.2016.09.030

40. Zagryadskii VA, Latushkin ST, Malamut TY, Nokikov VI, Ogloblin $\mathrm{AA}$, Unezhev $\mathrm{VN}$, et al. Measurement of terbium isotopes yield in irradiation of 151Eu targets by $3 \mathrm{He}$ nuclei. At Energy. (2017) 123:558. doi: 10.1007/s10512-017-0299-8

41. Moiseeva AN, Aliev RA, Unezhev VN, Zagryadskiy VA, Latushkin ST, Aksenov NV, et al. Cross section measurements of $151 \mathrm{Eu}(3 \mathrm{He}, 5 \mathrm{n})$ reaction: new opportunities for medical alpha emitter $149 \mathrm{~Tb}$ production. Sci Rep. (2020) 10:508. doi: 10.1038/s41598-020-57436-6

42. Beyer GJ, Comor JJ, Daković M, Soloviev D, Tamburella C, Hagebø E, et al. Production routes of the alpha emitting $149 \mathrm{~Tb}$ for medical application. Radiochim Acta. (2002) 90:247-52. doi: 10.1524/ract.2002.90.5_2002.247

43. Alexander JM, Simonoff GN. Excitation functions for $149 \mathrm{gTb}$ from reactions between complex nuclei. Phys Rev. (1963) 130:2383. doi: 10.1103/PhysRev.130.2383

44. Kossakowski R, Jastrzebski J, Rymuza P, Skulski W, Gizon A, Andre $\mathrm{S}$, et al. Heavy residues following 5-10 MeV/nucleon $12 \mathrm{C}$ and $14 \mathrm{~N}$ induced reactions on Sm and $\operatorname{Pr}$ targets. Phys Rev C. (1985) 32:1612. doi: 10.1103/PhysRevC.32.1612

45. Maiti M. New measurement of cross sections of evaporation residues from the nat $\mathrm{Pr}+12 \mathrm{C}$ reaction: a comparative study on the production of $149 \mathrm{~Tb}$. Phys Rev C. (2011) 84:044615. doi: 10.1103/PhysRevC.84.044615

46. Beyer GJ, Offord R, Allen BJ, Groozee G, Imam S, Sarkar S, et al. Targeted cancer therapy: the potential role of terbium-149. CERN-PPE/96-127 (1996).

47. Lahiri S, Nayak D, Das SK, Ramaswami A, Manohor SB, Das NR. Separation of carrier free 152,153Dy and 151-153Tb from 16O7+ irradiated $\mathrm{CeO} 2$ by liquid-liquid extraction. J Radioanl Nucl Chem. (1999) 241:2016. doi: 10.1007/BF02347313

48. Lahiri S, Nayak D, Das SK, Ramaswami A, Manohor SB, Das NR. Separation of carrier free dysprosium and terbium isotopes from $12 \mathrm{C} 6+$ irradiated $\mathrm{Nd} 2 \mathrm{O} 3$. Appl Radiat Isot. (1999) 51:27-32. doi: 10.1016/S0969-8043(98)00189-4

49. Nayak D, Lahiri S, Ramaswami A, Manohor SB, Das NR, Separation of carrier free $151,152 \mathrm{~Tb}$ produced in $16 \mathrm{O} 6+$ irradiated lanthanum oxide matrix. Appl Radiat Isot. (1999) 51:631-6. doi: 10.1016/S0969-8043(99) 00106-2

50. Engle JW, Bach H, Couture A, Gritzo R, Smith DM, Bitteker LJ, et al. Cross sections for proton induced reactions on terbium at $200 \mathrm{MeV}$. AIP Conf Proc. (2012) 1509:152-6. doi: 10.1063/1.4773958

51. Gayoso R, Barral M, Nassiff S. $\left(\begin{array}{lllllll}\alpha, & 3 p & \mathrm{xn}\end{array}\right)$ or $\left(\begin{array}{lll}\alpha, & \alpha \mathrm{p} & \mathrm{xn}\end{array}\right)$ reactions on natural dysprosium. J Radioanal Nucl Chem. (1997) 218:223-7. doi: 10.1007/BF02039339
52. Rath PK, Santra S, Singh NL, Nayak BK, Mahata K, Palit R, et al. Complete fusion in $7 \mathrm{Li}+144,152 \mathrm{Sm}$ reactions. Phys Rev C. (2013) 88:044617. doi: 10.1103/PhysRevC.88.044617

53. Franz EM, Friedlander G. Cross sections for production of $149 \mathrm{~Tb}$ from Au by high energy protons. Nucl Phys. (1966) 76:121-8. doi: 10.1016/0029-5582(66)90963-1

54. Heydegger HR, Van Ginneken A. Production of $149 \mathrm{~Tb}$ from gold by 0.2 to $0.5 \mathrm{GeV}$ protons. Nucl Phys A. (1972) 196:15660. doi: 10.1016/0375-9474(72)90957-8

55. Allen BJ, Goozee G, Sarkar S, Beyer G, Morel C, Byrne AP. Production of terbium-152 by heavy ion reactions and proton induced spallation. Appl Radiat Isot. (2001) 54:53. doi: 10.1016/S0969-8043(00)00164-0

56. Verhoeven H, Cocolios TE, Dockx K, Farooq-Smith GJ, Felden O, FormentoCavaier R, et al. Measurement of spallation cross sections for the production of terbium radioisotopes for medical applications from tantalum targets. Nucl Inst Meth Phys Res B. (2020) 463:327-9. doi: 10.1016/j.nimb.2019. 04.071

57. dos Santos Augusto RM, Buehler L, Lawson Z, Marzari S, Stachura M, Stora $\mathrm{T}$, et al. CERN-MEDICIS (medical isotopes collected from ISOLDE): a new facility. Appl Sci. (2014) 4:265-81. doi: 10.3390/app4020265

58. Andrighetto A, Tosato M, Ballan M, Corradetti S, Borgna F, Di Marco V, et al. The ISOLPHARM project: ISOL-based production of radionuclides for medical applications. J Radioanal Nucl Chem. (2019) 322:73-7. doi: 10.1007/s10967-019-06698-0

59. Choudhury D, Lahiri S, Naskar N, Delonca M, Stora T, Ramos JP, et al. Quantification of radioisotopes produced in $1.4 \mathrm{GeV}$ proton irradiated Lead-Bismuth Eutectic targets. Eur Phys J A. (2020) 56:204. doi: 10.1140/epja/s10050-020-00191-z

60. Subhodaya CR, Biswas BS, Kulloli Nair VC. Separation of carrier free $161 \mathrm{~Tb}$ from neutron irradiated gadolinium. Proc Radiochem Radiat Chem Sym. (1982).

61. Webster B, Ivanov P, Russell B, Collins S, Stora T, Ramos JP, et al. Chemical purification of terbium-155 from pseudo-isobaric impurities in a mass separated source produced at CERN. Sci Rep. (2019) 9:10884. doi: 10.1038/s41598-019-47463-3

62. Aziz A, Artha WT. Radiochemical separation of $161 \mathrm{~Tb}$ from $\mathrm{Gd} / \mathrm{Tb}$ matrix using $\mathrm{Ln}$ resin column. Indones J Chem. (2016) 16:283-8. doi: $10.22146 /$ ijc. 21143

63. Maiti M, Lahiri S, Tomar BS. Investigation on the production and isolation of $149,150,151 \mathrm{~Tb}$ from $12 \mathrm{C}$ irradiated natural praseodymium target. Radiochim Acta. (2011) 99:527-33. doi: 10.1524/ract.2011.1839

64. Zaitseva NG, Dmitriev SN, Maslov OD, Molokanova LG, Starodub G, Shishkin SV, et al. Terbium-149 for nuclear medicine. The production of $149 \mathrm{~Tb}$ via heavy ions induced nuclear reactions. Czech J Phys. (2003) 53:A455-8. doi: 10.1007/s10582-003-0058-z

65. Dmitriev SN, Beyer GJ, Zaitseva NG, Maslov OD, Molokanova LG, Starodub $\mathrm{G}$, et al. Lanthanides in nuclear medicine: preparation of $149 \mathrm{~Tb}$ by irradiation with heavy ions. Radiochem. (2002) 44:171-3. doi: 10.1023/A:1019627514277

66. Aziz A. Physico-chemical characterization of the terbium-161 radioisotope through separation based on cartridge LN resin column from irradiated of enriched Gd2O3 target. IOP Conf Series J Phys. (2020) 1436:012097. doi: 10.1088/1742-6596/1436/1/012097

Conflict of Interest: The authors declare that the research was conducted in the absence of any commercial or financial relationships that could be construed as a potential conflict of interest.

Copyright (๑) 2021 Naskar and Lahiri. This is an open-access article distributed under the terms of the Creative Commons Attribution License (CC BY). The use, distribution or reproduction in other forums is permitted, provided the original author(s) and the copyright owner(s) are credited and that the original publication in this journal is cited, in accordance with accepted academic practice. No use, distribution or reproduction is permitted which does not comply with these terms. 